\title{
The Moderating Role of Risk Perception on The Relationship Between Satisfaction and Repurchase Intention of Bottled Water in Nigeria: A Research Proposition
}

\author{
Abdul Wahid N. ${ }^{1,}{ }^{*}$, Mohaidin Z. ${ }^{1}$ and Ojatta D. O. ${ }^{1}$ \\ ${ }^{1}$ Graduate School of Business, Universiti Sains Malaysia (USM), 11800, Pulau, Pinang, Malaysia
}

\begin{abstract}
There has been a surge of bottled water consumption globally to date. This phenomenon requires investigation on why consumers intend to repeat purchase the product. While past literature has applied Oliver's expectation disconfirmation theory (EDT) to explain the link between customer satisfactions (CS) and repurchase intention (RI), other studies have reported conflicting findings. Thus, this study argues that risk perception (RP) should be added as a moderating variable between CS-RI which should improve our understanding of the RI behaviour in the context of EDT, bottled water consumption, policy and marketing strategy research. A new framework is proposed to explain the role of RP in EDT, with the aim of stimulating further enquiry.
\end{abstract}

\section{Introduction}

There is a surge of bottled water consumption across the globe to date. China, United States and Mexico were the top three country consumers of BW in a released compounded annual growth rate (CAGR) of bottled water between 2009 and 2014 [1]. China for instance consumed $15 \%$ more BW in 2014 than they did in 2009 (from 5,692.30 to $11,459.00$ millions of gallons) followed by $5.2 \%$ for United States (from $8,453.10$ to $10,874.80$ millions of gallons) and by $4.6 \%$ for Mexico (from 6,891.60 to 8,645.30 millions of gallons) in the same evaluated period. The surge in consumption is also observable for Thailand, India and Indonesia with $20.2 \%, 13.2 \%$ and $12.5 \%$ CAGR of BW respectively. In sum, the global CAGR has increased by almost $7 \%$ amounting to 74 billion gallons or 2.83 trillion litres between the period [1] ahead of any other in the beverages category. Eighty percent of the growth occurred in only ten countries, namely the US (North America), Mexico, Brazil (South America), Italy, France and Germany (Europe). Others are China, Indonesia, Thailand, and India (Asia).

While the global increase of BW consumption may be due to consumers' perception that BW is safer for drinking than tap water [2], studies have reported violation of $\mathrm{BW}$ quality standard and guidelines across the globe[3-6]. The question is why do consumers still repurchase or have intention for repurchase the product whose quality is doubtful? The ability for researchers and practitioners to explain the RI behaviour will provide an insight to consumer behaviour literature, marketing strategy and policy research particularly as these help them understand customer retention (CR). $\mathrm{CR}$ has been linked to increased revenue [7], reduced cost of transactions [8], competitive edge [9] profitability [10-11], and long term growth [12].

A review of the literature indicates that the expectation disconfirmation theory (EDT) by Oliver [13] have been popularly adopted or adapted to help explain customer RI behaviours for examples [14-21]. However, research conclusions are emerging that CS with a product does not necessarily mean he will repurchase the product [22-23]. This brings about conflicting findings on the effect of CS on RI. Consequently, prescriptive model needs to be conceptualized. In this study, while all variables in Oliver's EDT are retained as the base of model, risk perception (RP) is proposed to moderate CS-RI relationship. Baron and Kenny recommend adding a variable as a moderator when findings on the relationship between variables are inconsistent [24]. Further, Oliver and Burke had also recommended modification of the EDT model which is discussed in the next section [13].

\section{The Expectation Disconfirmation Theory}

The EDT has dominated CS/D research over the past couple of decades; flaunted as one of the most versatile model for the study of human behaviours and has been applied in various study domains such as product [25], services [26], online studies [12], [27], governance and policy [28]. Others are education [29], health [30], and family life and marriage [31-32]. Though some earlier studies [33-35] had investigated the disconfirmation as a variable, much of the credit for the evolution of EDT 
are ascribed to the numerous works of Oliver and his colleagues [13].

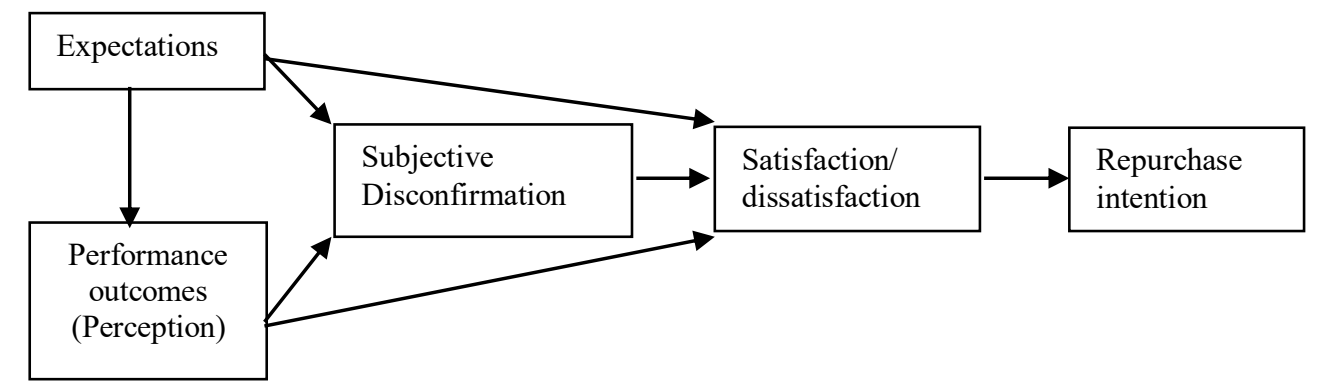

Fig. 1. A model of Expectation Disconfirmation Theory (EDT). Oliver and Burke (1999)

Precisely, the theory has been used or adapted to report assimilation effects for less experienced IT users (16) negative disconfirmation of Employment Assistance Services (EAS) among employees of South African Police Service (SAPS) and relationship between student's level of group satisfaction, engagement and positive performance [36]. Further, EDT has also been applied to investigate the predictors of web customer's repurchase intention in Taiwan [22], users' continuance intention towards e-learning [10], information systems (IS) users' continuance intention [14], as well as the effects of perceived customization and perceived sociability on CS and RI amongst consumers of virtual products [37]. To that effect, p.1190 [38], conclude that research in the field of consumer behaviour "has been grounded theoretically in the expectation-disconfirmation model".

Essentially, the theory is important because it has been used to explain the basis for customer assessment of product or service offerings, what factors deliver higher customer satisfaction and why consumers like or dislike certain offerings. It has also been used in explaining what customers do when they are satisfied and when they are not. In the model,

customer expectation (CE), the customers' pre-trial beliefs about a product [39] is posited as antecedent of performance outcome i.e. perception (CP), subjective disconfirmation (D) and customer satisfaction (CS). Similarly, CP which is a customer's subjective view of how a product performed compared to pre-trial beliefs, is modelled as an antecedent of both D and CS while $\mathrm{D}$, tagged as a subjective feeling of how worse or better a product has performed compared to intial expectation is modelled as an antecedent of satisfaction. Finally, satisfaction is posited to be positively related to RI.

The theory holds that if $\mathrm{CE}$, that is the standard against which CP, D and CS are measured is high, then CP, D and CS will likely be high because customers will assimilate any discrepancy that might have occurred (assimilation theory). This will likely occur under the conditions that the discrepancy is within the zone of or the level of effort expended in the purchase process is high [40]. This is also the position of cognitive dissonance theory [34]. [33] report high CE will lead to high evaluation. Also [35] confirmed that high $\mathrm{CE}$ is positively related to customer product evaluation. On the contrary, customers are likely to magnify the discrepancy (contrast theory) when a customer's product evaluation is lower than expectation [33], especially when the discrepancy is outside the zone of tolerance [40]. D and CP equally modelled as antecedents of CS, just as CS is modelled to predict repurchse intention (RI). It is believed that positive quality evaluation and disconfirmation will increase CS and vice versa, which affects a customer's decision to re-buy. Therefore, CS with product quality is regarded as vital because it is one of the major components of customer behaviour [33].

\subsection{The gap}

Despite the vast application of EDT in investigating consumer RI, the potential threat to the model is the faltering effect of CS on RI. Literature reports diversity of findings in the link between CS and RI. For example whereas some report direct link between CS and RI [13 , 41-43], others differ in their findings [22, 44-45]. It does not matter whether all these studies adopted EDT or not, because deductive studies underlined by positivist world-views believe there is a "single reality". If the relationship between CS and RI has become inconsistent in some models, this could hold EDT, thereby making it essential to introduce a moderator in a prescriptive model.

Introducing RP as a moderator in the CS/RI link is predicated on the inconsistent findings on the relationship between CS and RI and the importance and relevance of RP as a predictor variable in customers' purchase decisions. The research tradition posits that when findings on the relationship between a predictor and a response variable are weak or inconsistent [23], a third variable called the moderator may be introduced. RP is an important predictor variable in customers' purchase decision [47]. Baron and Kenny state that moderator variables always function as predictor variables [23]. Previous research [48-49], confirms RP as a predictor. Further, related studies suggest that RP is a likely variable that could moderate the CS/RI link, because it is an important antecedent variable in consumption of bottled water 
[50]. Specifically, Bauer "proposed that consumer behaviour be seen in the theoretical framework of risk taking" [51]. This study therefore introduces RP as a moderator between CS and RI link.

\subsection{Risk perception}

RP is the level of perceived, potentially negative consequences attached to a purchase decision. It is a decision maker's evaluation of the risk present in a situation [52]. It is also considered "the negative consequences that can arise from the purchase of a product" [53] RP is considered "fundamental to the understanding of consumer choice behaviour" [47]. that is likely to affect consumer behaviour" in ecommerce [54]. In the context of drinking water, it is a person's subjective evaluation of a drinking water quality in terms of aesthetic and non-aesthetic attributes [55]. A significant number of decisions involve some measures of uncertainty which can be positive or negative. If the uncertain future outcome includes likelihood of negative results, it can be said that the decision is risky. Contextually, the antecedents of RP of BW include organoleptics and external information among [50]. Concede that RP is informed by the level of awareness of drinking water problem
[56]. Back to the EDT, since the only portion that is susceptible to threat of inconsistency is the CS/RI link, the remaining part of this paper focuses on RP and the $\mathrm{CS} / \mathrm{RI}$ relationships.

\subsection{The conceptual framework and proposition}

Evidently, our prescriptive model is adapted from the EDT discussed in a previous section. From the literature, the predictors of CS include CE, CP and D as shown in Figure 2. The relationship between consumer satisfaction (CS) and RI is well documented in the literature. According to $[41,23]$. CS is a predictor of behavioural intention which includes repurchase intention. In another study it was established that customers' repurchase intention (i.e. intention to continue IS use) was predicated by satisfaction [14]. Additionally, it has been found that $\mathrm{RI}$ is related to satisfaction with previous visits [57], and directly affected by CS [42]. Report that satisfaction is associated with online continuance intention.) also associated CS with RI as confirmed by [59]. Recently too, Izogo finds that satisfaction primes repurchase intention [43].

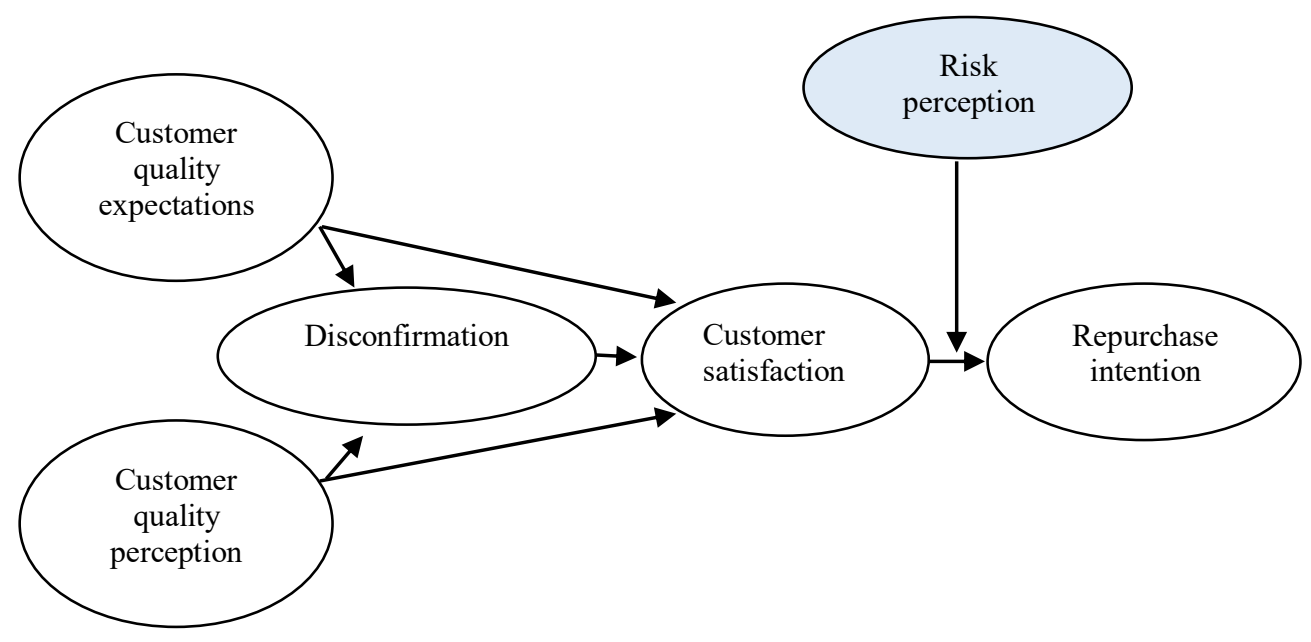

Fig. 2. Customer expectation and satisfactionSource: Adapted from (Oliver \& Burke, 1999)

\subsection{The moderating role of risk perception on CS/RI relationship}

A moderator is a predictor variable which when introduced into a relationship between another predictor and a response variable, weakens, strengthens or changes the direction of the relationship. According to past studies [23] certain conditions must exist to justify introduction of a moderator in a research. One of such is that there should be inconsistency in findings about the relationship from the literature. Furthermore, introduction of a moderator becomes plausible if such relationship is found to be consistently weak.

In the situation under consideration, extant literature presents conflicting findings on the relationship between CS and RI. Whereas the normative model associates CS with RI [13, 41-43], other [21-22, 44-46] are divergent in conclusions. The literature indicates that RP can impact the relationships between variables in decision-making. Previously, it has been shown that RP moderate the relationship between incongruity and evaluations as well as being related to use intention. Featherman and Fuller reports that, moderating effect of RP such that higher levels of RP weakens the effect of ease of use on perceived usefulness and adoption intention. Additionally, observe a need for a theoretical basis for the integration of RP as probable direct influences on purchase intention. This necessitates introducing RP to moderate the CS/ RI link in this study. Based on above 
conditions, we propose as follows. Proposition: The higher the customers' risk perception, the weaker the $\mathrm{CS} / \mathrm{RI}$ relationship.

\section{Summary and Directions for Future Research}

Understanding repurchase intention, a predictor of repurchase, is necessary because it is critical to firms' competitive advantage, consumer price tolerance, low operating costs, profitability and long term growth. Though prior research largely point to customer satisfaction as a major antecedent, findings on this relationship remains inconsistent. While some studies find direct association, others find indirect or none at all. To deepen our understanding of this phenomenon, this study develops a research framework and a research proposition that will support future research on consumer repurchase intention. To successfully accomplish this, a theory/industry interface is needed to test the framework. This leads to selection of the expectation disconfirmation theory (EDT) and the bottled water (BW) sub-sector. While the EDT is one of the most appropriate and versatile in the study of consumer behaviours, the BW sub-sector is the fastest growing in the beverage industry, with a market value of US\$169.9 bn in 2015 which is expected to reach US $\$ 307.2$ bn by 2024 [60].

The problem with this industry is that while consumers prefer BW because it is perceived as being free from health risks, empirical evidence points to significant quality standard violation by practitioners. Given this background, it becomes unclear why bottled water consumption is increasing as quality guidelines violation increased instead of the other way round. Based on these, this study advances a framework needed to aid future research on BW consumption, policy and marketing strategy, and extend the EDT. The framework links customer satisfaction and its antecedents to repurchase intention and expands the expectation disconfirmation theory by incorporating risk perception to moderate the link between CS and RI. The proposition that evolve out of the framework present opportunity for future empirical research. The issue in focus is understanding consumers' intention BW that is lacks quality assurance because of the violations of quality standard by practitioners. Researchers' and practitioners' ability to explain the consumers' RI behaviour will provide some understanding to consumer behaviour literature, marketing strategy and policy research, and customer retention (CR) which has been linked to increased revenue, reduced cost of transactions, competitive edge, profit possibilities and long term business growth.

\section{References}

1. J. G. Rodwan, International Developments and Statistics, ://www.bottledwater.org/economics/industrystatistics. (New York, 2015)

2. C. Fornell, J. Market., 56(1), 6-21 (1992)

3. A. Azlan, H. E. Khoo, M. A. Idris, A. Ismail, M. R. Razman, Sc. W. J., 1-10 (2012)

4. Z. Hu, L. W. Morton, R. Mahler, Int. J. Envi. Res. Pub. H., 8(12), 565-578 (2011)

5. O. A. Igbeneghu, A. Lamikanra, BMC Research Notes, 7, 859 (2014)

6. W. K. Viscusi, J. Huber, J. Bell, Cont. Eco. Pol., 33(3), 450-467. (2015)

7. V. Mittal, C. Frennea, R. A. Westbrook, Marketing Review St. Gallen, 31(3), 46-54. (2014)

8. J. N. Cannon, C.A. Denison, Verifiable Detail as a Valid Source of Disclosure Credibility In NonFinancial Strategy. http://haskayne.ucalgary.ca/files/haskayne/Cannon -and-Denison.pdf (2014)

9. J. J. J. Cronin, M. K. M. K. Brady, G.T. M. Hult, J. Retail., 76(2), 193-218 (2000)

10. K. C. Murigi, K. Ombui, Int. J. Sc. Res, 3(3), 192$196(2014)$

11. V. A. Zeithaml, L. L. Berry, J. Parasuraman, Aca. Market. Sc., 21(1), 1-12 (1993)

12. C. Lin, W. Lekhawipat, Factors, Ind. Man. Data Sys., 114(4), 597-611 (2014)

13. R. L. Oliver, R. R. Burke, Expectation Processes in Satisfaction Formation: A Field Study, 1(3), 196-214 (1999)

14. A. Bhattacherjee, Dec. Supp. Sys., 32(2), 201214 (2001)

15. E. Ko, J. G. Aca. Market. Sc., 4(1), 197-211 (1999)

16. N. K. Lankton, H. D. Mcknight, J. Assc. Info. Sys., 13(2), 88-115 (2012)

17. E. Y. Li, J. C. Hsiao, J. A. Yang, H. R. Yen, The 9th International Conference on Electronic Business, Macau (2009)

18. V. Venkatesh, S. Goyal, MIS Quarterly, 34(2), 281-303 (2010)

19. W. T. Wang, W. H. Chang, Info. Sys. Frontiers, 16(5), 887-908 (2014)

20. Y. Yi, S. La, Serv. Ind. J., 23(5), 20-47 (2003) 
21. Chang K.C., M. C. Chen, C. L. Hsu, N. T. Kuo, Industrial Management \& Data Systems, 110, 1420-1443 (2010)

22. H. Saleem, N. S Raja, Middle - East J. Sc. Res., 19(5), 706-711 (2014)

23. R. M. Baron, D. Kenny, J. P. Soc. Pscho. 51(6), 1173-1182. (1986)

24. D. Baum, M. Spann, J. Füller, Proceedings of the 21st European Conference on Information Systems, 1, (2013)

25. Int, Rev. Retail, Dis. Con. Res., 6(1), 1-33 (1996)

26. M. Kim, C. A. Vogt, B. J. Knutson, J. Hosp. Tour. Res., 39(2), 170-197. (2015)

27. T. H. Poister, J. C. Thomas, J. Pub. Admin. Res. Theo., 21(4), 601-617 (2011)

28. R. Jacobsen, J. W. Snyder J. Pub. Admin. Res. Theo., 25(3), 831-848 (2015)

29. T. N. Cassidy-Smith, B. M. Baumann, E. D. Boudreaux, J. E. Med., 32(1), 7-13 (2007)

30. J. Guttmann, A. Lazar, J. Repro. I. Psycho., 22(3), 147-156 (2004)

31. D. M. Sagiv-Reiss, G. E. Birnbaum, M. P. Safir, M. P., Arch. Sex. Beha., 41(5), 1241-1251 (2012)

32. R. N. Cardozo, J. Market. Res., 2, 244-249 (1965)

33. L. Festinger, A Theory of Cognitive Dissonance, (Stanford University Press, 1962)

34. R. W. Olshavsky, J. A. Miller, J. Market. Res., 9(1), 19 (1972)

35. C. Schwarz, Z. Zhu, J. Info. Sys. Edu., 26(1), 4759 (2015)

36. W. T. Wang, W. H. Chang, Info. Sys. Frontiers, 16(5), 887-908 (2014)

37. V. Martínez-Tur, N. Tordera, J. M. Peiró, J. App. Soc. Psycho., 41(5), 1189-1213 (2011)

38. V. McKinney, K. Yoon, F. Zahedi, F. Info. Sys. Res., 13(3), 296-315 (2002)

39. V. A. Zeithaml, L. L. Berry, A. Parasuraman, J. Market., 60(4), 31-46 (1993)

40. M. C. Lee, Com. Edu., 54(2), 506-516 (2010)

41. E. W. Anderson, C. Fornell, D. R. Lehmann, J. Market., 58(3), 53-66 (1994)

42. C. Huang, S. Yen, C. Liu, T. Chang, Int. J. Org. Inno., 6, 106-121 (2014)

43. E. E. Izogo, Int. J. E. Market., 11(3) (2016)

44. Y. Chen, H. Huaang, Y. Hsu, Com. Info. Sc., 3(3), 14-22. (2010)
45. S. Jose, N. Khare, F. R. Buchanan, Int. J. Bank Market., 33(3), 316-329 (2015)

46. L. P. Pleshko, R. A. Heiens, Int, Rev. Retail, Dis. Con. Res., 25(1), 55-71 (2015)

47. V.-W. Mitchell, P. J. McGoldrick , Int. Rev. Ret., Dist. Con. Res., 6(1), 1-33 (1996)

48. D. T. Griffee, An Introduction to Second Lanaguage Research Methods: Design and Data. TESL-EJ Publications Berkeley, (eBook edit). (Berkeley, California, USA: TESL-EJ Publications, 2012)

49. F. J. Hair, J. M. Sarstedt, L. Hopkins, V. G. Kuppelwieser, V., A Primer on Partial Least Squares Structural Equation Modeling (PLSSEM). European Business Review, 26, (Washington: Sage Publications, 2014)

50. M. de F. Doria, N. Pidgeon, P. R. Hunter, Sc. Tot. Envi., 407(21), 5455-5464 (2009)

51. J. N. Sheth, M. Venkatesan, S. J. Market. Res., 5(3), 307-310 (1968)

52. Sim B. Sitkin and Amy L. Pablo, Aca. Man. Rev., 17, 1, 9-38 (1992)

53. F. V. Wangenheim, J. Ser. Res., 8(1), 67-78 (2005)

54. A. Pavlou, Pavlou, Int. J. Elec. Comm., 7(3), 101134 (2003)

55. A. K. Harding, E. C. Anadu, J. A. Water Works Assc, 92(8): 32-41 (2000)

56. M., Holm, Hansen., TOC, 12(4), 333-352 (2013)

57. A., Camarero, L. García,, 1080/13683500.2014.936834 (2014)

58. N. Mohamed, Ramlah Hussein, Nurul Hidayah Ahmad Zamzuri, Hanif Haghshenas, Ind. Man. Data Systems, https://doi.org/10.1108/IMDS-072014-0201, 114(9), 1453-1476 (2014)

59. M., Faullant, Renzl, Leiter, The Relationship between Personality Traits Extraversion and Neuroticism Emotions and Customer Self Satisfaction (2005)

60. Transparency Market Research., Global Bottled Water Market : Rising Health Concerns to Drive Demand for Healthy and Hygienic Products, states TMR, (New York, 2016)

61. M. Morgan, X. D., J. Inter. Res., 13(2), 44-58 (2008)

62. M. F. Doria, J. W. H., 27:232.3), 2, 271-276. (2006)

63. C. Ferrier, AMBIO: J. Human Envi., 30(2), 118119. (2001) 
64. F., L., A Theory of Cognitive Dissonance. (Stanford University Press, 1962)

65. B. Karoubi, R. Chenavaz, C. Paraschiv, App. Eco., 48(14), 1317-1329. (2015)

66. K., E., J. G. Aca. Market. Sc., 4(1), 197-211. (1999).
67. N. Lankton, D. H. McKnight, J. B. J. Thatcher, J. S. Info. Sys., 23(2), 128-145. (2014)

68. E. D. Olson, Bottled Water: Pure Drink or Pure Hype? National Resources Defense Council. https:/www.nrdc.org/sites/default/files/bottledwater-pure-drink-or-pure-hype-report.pdf. (1999) 